ISSN:2528-9527

E-ISSN : 2528-9535

YIl Year: 8

Cilt Volume: 9

Sayı Issue : 16

\title{
Coach 4 Me: Öğretmen Eğitiminde Kullanılabilecek Bir Leonardo Da Vinci Projesi Deneyimi
}

DOI: $10.26466 /$ opus. 498760

\author{
E. Zehra Turan ${ }^{*}$ - Aysun Erginer ${ }^{* *}$ - Ergin Erginer ${ }^{* * *}-$ Funda N. Yllmaz ${ }^{* * * *}$
}

*Dr. Öğr. Üyesi, Nevşehir Hacı Bektaş Veli Üniversitesi, İlahiyat Fakültesi, Nevşehir / Türkiye, E-Posta: zturan@nevsehir.edu.tr ORCID: 0000-0001-5635-0032

${ }^{*}$ Doç. Dr., Nevşehir Hacı Bektaş Veli Üniversitesi, Eğitim Fakültesi, Nevşehir / Türkiye,

E- Posta: aysunerginer@nevsehir.edu.tr ORCID: 0000-00002-0029-4032

${ }^{* * *}$ Doç. Dr., Nevşehir Hacı Bektaş Veli Üniversitesi, Eğitim Fakültesi, Nevşehir / Türkiye,

E- Posta: erginerginer@nevsehir.edu.tr ORCID: $0000-0002-7590-4755$

${ }^{* * * *}$ Dr. Öğr. Üyesi, Nevşehir Hacı Bektaş Veli Üniversitesi, Eğitim Fakültesi, Nevşehir / Türkiye

E- Posta: fundan@nevsehir.edu.tr ORCID: 0000-0002-3228-4605

Öz

Yaşam boyu öğrenmeye yönelik çeşitli uygulamalar, Avrupa Birliği (AB) tarafından ERASMUS+ Leonardo da Vinci Programı kapsaminda desteklenmekte, ülkelerin ulusal ajansları ve sivil toplum kuruluşları aracılığıyla projelendirilmektedirler. Leonardo da Vinci Programı, AB'ye üye ve aday ülkelerin mesleki eğitime yönelik politika ve uygulamaların desteklemek ve geliştirmek için yürütülen bir eğitim programıdır. Bu eğitim programı kapsamında hazırlanan projelerden birisi de "Coach $4 \mathrm{Me}$ " isimli projedir. "Coach $4 \mathrm{Me}$ ", 6 ülke tarafindan yürütülen ve öğretmenlerle akademisyenlerin öğretim becerilerinin geliştirilmesinin amaçlandığ kitlelere tanıtılması ve öğretimsel etkinliklerin, süreç sonrasında da farkl eğitsel ortamlarda kullanılması, projede sürdürülebilir amaçlar olarak belirlenmiştir. Çalışmada, bir AB projesi olan "Coach 4 $M e$ " tanttılarak, projenin amaçlar arasında yer alan "daha geniş kitlelere ulaşma" amacının gerçekleştirilmesine çalışılmıştır.

Anahtar Kelimeler: Avrupa Birliği Ĕ̆itim Programları, Avrupa Birliği Projeleri, Coach $4 \mathrm{Me}$, Öğretim, Öğretimsel Etkinlikler

OPUS (c) Uluslararası Toplum Araştırmaları Dergisi-International Journal of Society Researches ISSN:2528-9527 E-ISSN : 2528-9535

http://opusjournal.net 
ISSN:2528-9527

E-ISSN : 2528-9535

YIl Year: 8

Cilt Volume: 9

Sayı Issue :16

Uluslararası Toplum Araştırmaları Dergisi International Journal of Society Researches

Aralık December 2018

Makalenin Geliş Tarihi Received Date:10/12/2018

Makalenin Kabul Tarihi Accepted Date: 28/12/2018

\title{
Coach 4 Me: Experience of a Leonardo Da Vinci Project for Teacher Education
}

\begin{abstract}
Various applications for lifelong learning are supported by the European Union (EU) as part of the ERASMUS + Leonardo da Vinci Program and are projected through national agencies and nongovernmental organizations. The Leonardo da Vinci Program is a training program to support and develop the policies and practices of EU member and candidate countries for vocational education. Within the scope of this training program one of the projects prepared is "Coach $4 \mathrm{Me}$ " named project. "Coach $4 \mathrm{Me}$ " is a project which aimed to improve the teaching skills of teachers and academics was carried out by including 6 countries. Introducing the project to a wider audience and using instructional activities in different educational environments after the process have been determined as sustainable objectives in the project. In the study, the Coach $4 \mathrm{Me}$ ", which is an EU project, was introduced, "to reach a wider audience" which is among the aims of this project.
\end{abstract}

Keywords: European Union Education Programs, European Union Projects, Coach 4 Me, Teaching, Instructional Activities

OPUS (c) Uluslararası Toplum Araştırmaları Dergisi-International Journal of Society Researches ISSN:2528-9527 E-ISSN : 2528-9535

http://opusjournal.net 


\section{Giriş}

Dünyadaki tüm ülkeler gibi Türkiye de teknolojinin hizla ilerlemesiyle, bir değişim ve dönüşüm sürecinden geçmektedir. Avrupa ülkelerinden bazıları, geleceklerini kendi aralarında ekonomik, sosyal, politik ve teknolojik alanlarda işbirliği yapmakta görmüşler ve farklı isimlerle faaliyet gösteren toplulukların ardından, Avrupa Birliği (AB)'ni oluşturma yoluna gitmişlerdir. AB ülkeleri, kültürel ve bölgesel farklılıklarına rağmen "barış, demokrasi, hukukun üstünlüğü ve insan hakları" ilkelerinde birleşirler. AB kapsamında bu değerleri yaşatmak, yaymak ve dünya genelinde paylaşmak için çalışan ülkeler, bu konuda farklı projeler ve uygulamalara yönelmektedirler. $\mathrm{AB}$ ülkeleri arasında aday ülke olarak yer alan Türkiye de, sürece doğal bir şekilde katılmıştır. Bununla birlikte, eğitim göstergeleri açısından (Maya, 2006) üye ülkelere göre dezavantajlı bir konumdadir.

AB ekonomik ve politik bir birlik olarak düşünülse de, aslında "kültürel ve eğitsel" alanlarda da sürekli gelişimi ilke edinmektedir. Türkiye' nin yakın geçmişinde ve geleceğinde önemli bir konumda olan $A B$ ülkeleri ile hukuki, ekonomik işbirliğinin yanında, eğitim konusunda da bazı anlaşmalar yapılmaktadır. Türkiye, isimleri zaman zaman değişen “Sokrates, Erasmus, Yaşam Boyu Öğrenme ve Gençlik Programları vb." paydaşı konumundadır. Bu bağlamda anlaşmalar imzalanmış ve eğitim programları ortaklıkları oluşturulmuştur. “Türkiye Yükseköğretim Yeterlilikler Çerçevesi (TYYÇ)" oluşturulmuş, yükseköğretim sistemi içerisinde yer alan yükseköğretim ile mesleki eğitim alanlarında "Alana Özgü Yeterlilikler" tanımlanmıştır. Böylece ilgili alan yeterlilikleri doğrultusunda, yükseköğretim kurumlarının eğitim öğretim programlarının yapılandırılması ve sürekli güncellenmesi sağlanmıştır. Artık, eğitim alanında yerel olmaktan uluslararası düzeye ulaşılmaya çalışılmaktadır. Kulaksız (2010), eğitimde küreselleşmenin yollarından birisinin AB Eğitim Programları (EUEP) gibi uluslararası eğitim çalışmalarına katılmak olduğunu ifade etmektedir. AB Eğitim Programları, ortak bir bütçe havuzundan faydalanarak, $\mathrm{AB}^{\prime}$ ye üye ya da aday ülkelerin eğitim seviyelerini geliştirmek ve belli bir seviyeye ulaştırmak amacı ile yararlandıkları eğitsel programlardır. Bu programlar ekonomik, sosyal ve kültürel alanlarda gelişme ve 
bütünleşme için önemlidir. Türkiye, AB eğitim programlarına katılarak bir bakıma eğitimde küreselleşme hareketlerine adım atmış olmaktadır.

“AB Eğitim ve Gençlik Programları'nın hedefleri; çok uluslu eğitim, mesleki eğitim ve gençlik ortaklıkları oluşturmak; yeni yaklaşımları hedefleyen eğitim ve öğretim projeleri üretmek; öğretim programlarının ve yurtdışında eğitim fırsatlarının değişimini sağlamak; ülkeler arasında akademik ve mesleki uzmanlık ağları kurmak; açık ve uzaktan eğitim ile bilgi iletişim teknolojilerinin eğitim alanında kullanılmasına ve eğitimde çoklu ortam desteğinin sağlanmasına katkı sağlamak" (Ertl, 2003) olarak siralanabilir.

AB tarafından "2007-2013" yılları arasında yürütülen ve 2014 yılında sonlandırılan yaşam boyu öğrenme kapsamındaki mesleki eğitime yönelik hibeler, "2014-2020" yılları için Erasmus+ başlığı altına alınmıştır. Erasmus+ programıyla, eğitim, gençlik ve spor alanlarında 2020 yılına yönelik işbirliğine odaklanılmaktadır. Mesleki eğitimde ise becerileri geliştirmek, istihdamı sağlamak ve kaliteyi arttırmak amaçlanmaktadır (UA, 2011a, 2011b, 2015, 2018a).

Erasmus+ ismi altında $\mathrm{AB}$ eğitim programları, eğitim, gençlik ve spor alanlarında farklı yaş grupları ve hedef kitleye yönelik destekleyici bir programa dönüşmüştür. Okul eğitimi, yükseköğretim, mesleki eğitim, yetişkin eğitimi, gençlik ve spora ilişkin projeler, bu program kapsamında yer almaktadır. Yaşam Boyu Öğrenme Programları kapsamında olan “Comenius, Erasmus, Leonardo da Vinci, Grundtvig Programları ile Gençlik Programı ve 5 Uluslararası İşbirliği Programı (Erasmus Mundus, Tempus, Alfa, Edulink ve Sanayileşmiş Ülkelerle İşbirliği Programı)" da dahil edilerek Erasmus+ Programı başlığı altında toplanmıştır. Böylece tek bir program ile parçalı yapı uygulamasından vazgeçilerek başvuru koşulları sadeleştirilmiştir (UA, 2015, 2018b).

AB Eğitim ve Gençlik Programları'ndan “AB üyesi ülkeler, $A B$ üyesi olmayan program ülkeleri (Norveç, İzlanda, Lihtenştayn, İsviçre, Makedonya ve Türkiye) ve üçüncü ülkeler (Arnavutluk, Bosna Hersek, Kosova, Karadağ Cumhuriyeti, Sırbistan, Ermenistan, Azerbaycan, Belarus, Gürcistan, Moldova, Ukrayna, Cezayir, Mısır, İsrail, Ürdün, Lübnan, Libya, Fas, Filistin, Suriye ve Tunus)" (UA, 2018c) yararlanabilmektedirler. Türkiye'nin bu programlardaki görevli organı "Ulusal Ajans"tır. $\mathrm{AB}$ eğitim programları dört dönemde ele alınabilir ve Türkiye için bu 
katılımın en yoğun olarak gerçekleştiği dönem “2007-2013" yılları arasıdır. Bu dönemde Yaşam Boyu Öğrenme Programı çatısı altında yer alan "Mesleki Eğitim Programı olan Leonardo da Vinci" projeleri gerçekleştirilmiştir.

$\mathrm{AB}$ politikalarında yaşam boyu eğitim, özellikle üzerinde durulmakta olan bir konudur. Avrupa'da eğitimin sadece okulda verileceği düşüncesinden uzaklaşılarak, eğitim süreci sonrasında da insanların kendilerini geliştirmelerine yardımcı olunmaya çalışılır. Amaç, yediden yetmişe herkesin yaşamlarının her alanında ve her an eğitim sürecinden geçmesini, eğitim-öğretimi "yaşam felsefesi" haline getirmelerini sağlamaktır. Bu nedenledir ki Avrupa'da zorunlu eğitim süreleri olabildiğince uzatılmakta, bireyleri okula yönlendirecek teşviklerde bulunulmaktadır (Yazg1, 2010, s.74).

Yaşam Boyu Öğrenme Programı́n nın amacı, AB bünyesindeki eğitim ve öğretim kurumlarının ve sistemlerinin dünya kalitesinde bir referans noktası olabilmesi için bu kurumların arasında değişimleri, işbirliğini ve hareketliliği teşvik etmektir. Aynı zamanda katılımcı ülkelerdeki eğitim ve öğretim sistemlerinin modernleştirilmesi ve adaptasyonuna katkıda bulunmak, programın hareketlilik ve diğer işbirliği faaliyetlerine katılan bireysel vatandaşlara Avrupa katma değerinin kazandırılmasını sağlamak amaçlanmaktadır (Ünal, 2016, s.581-598).

Leonardo da Vinci Ortaklık Projeleri ise mesleki eğitim ile ilgili tüm kurum ve kuruluşların (okul, STK, KOBİ vb.) proje hazırlayarak katılabilecekleri türden projeler olup, Leonardo da Vinci Programı kapsamındaki "Leonardo Ortaklıkları", proje tabanlı bir faaliyettir. Ortaklık faaliyetinde ürün ya da çıktı amaçlı ve işbirliğini kuvvetlendirici nitelikte ortaklıklar oluşturularak, bu amaca yönelik çalışma ziyaretleri gerçekleştirmek amaçlanmaktadır. Leonardo da Vinci Mesleki Eğitim Programı Ortaklık Projeleri'ne 2009 yılında 135 başvuru yapılmış, bunlardan 45'i kabul edilmiş ve kabul edilen projelerin bütçesi 860.000 Avro olarak gerçekleşmiştir. 2010 yılında ise yaklaşık iki katı artışla 251 başvuru yapılmış, bunlardan 85'i kabul edilmiş ve kabul edilen projelerin bütçesi 1.400.000 Avro olmuştur (UA, 2011b).

Leonardo da Vinci Programı, ülkeler arası işbirliği yoluyla mesleki eğitim uygulamalarında kalitenin geliştirilmesini, yeniliklerin teşvik edilmesini ve eğitimde kaliteyi amaç edinmektedir. Programın birinci 
aşamasının hedefleri doğrultusunda ikinci aşamada da katılımcı ülkelerin mesleki eğitim sistemleri ve uygulamalarında kalitenin geliştirilmesi, yeniliklerin teşvik edilmesi ve eğitimde kalite alanlarında, kültürel çeşitliliği ve dil çeşitliliğini de dikkate alarak gerçekleştirdikleri etkinlikler desteklenmektedir (Uysal, 2004).

Avrupa Komisyonu'nun 2007 yılı “Topluluk Programları II, Leonardo da Vinci ve e-Öğrenme Final Değerlendirmesi" adlı raporunda projelerin "dil öğrenimi ve öğretimi, yenilik ve yeni öğretim yöntemlerinde olumlu değişim sağladığı, katılımcıların iletişim becerilerini, kültürel farkındalıklarını ve mesleki yeterliklerini geliştirdiği" sonuçlarına ulaşılmıştır (Kesik ve Balcı, 2016). Yaşamboyu öğrenme anlayışı çerçevesinde bireyin hızla değişen mesleki eğitim sistemine ve koşullarına uyum sağlamasını kolaylaştıran projeler, aynı zamanda kurumların rekabet güçlerinin arttırılmasına katkıda bulunacak yenilikçi araç ve yöntemlerin geliştirilmesine finansal destek sağlamaktadır ve projeler için başvurular kurumsal düzeyde yapılmaktadır (UA, 2011a).

Coach $4 \mathrm{Me}$ (Life Long Learning Programme, Leonardo da Vinci Projesi, No: 2013-1-TR1-LEO04-48030 1, Tarih: 01/04/2014-10/07/2015), Yaşamboyu Öğrenme Leonardo da Vinci programı kapsamında üretilen projelerden biridir. Coach 4 (for) Me, "bana koçluk et" anlamında kullanılmıştır. Sağlık, ekonomi, eğitim vb. pek çok alanda kullanılan koçluk, "uzman kişilerin uzmanlık alanlarına göre bilgi, birikim ve deneyimlerini paylaşmaları" anlamına gelmektedir. Passmore (2014) koçluğun, çalışanların gelişimi, performans (iş başarımı) artışı sağlama ve örgütsel değişim amacıyla kullanıldığını belirtmektedir. Koçlar, karşılıklı güvenin sağlanarak ve eleştirel yaklaşarak koçluk alanının öğrenilmesini, ilgi alanına göre davranış değişikliğinin oluşmasını amaçlamaktadırlar. Bu amaçlara ulaşmak için koçun ilişki kurma, sürdürme, etkili iletişim becerilerine ve hizmet alanlarının ihtiyacı olan koçluk tekniği, modeli veya yaklaşımını uygulama becerilerine sahip olması gerekmektedir. Öğretmenlerin de koçluk görevleri bulunduğundan, bu projede koçluğun öğretmen eğitimi ile ilişkilendirilmesi doğal karşılanmalıdır. 
Coach 4 Me projesi, Nevşehir Hacı Bektaş Veli Üniversitesi ${ }^{1}$ Uluslararası İlişkiler Ofisi ve Eğitim Fakültesi yürütücülügünde hazırlanmıştır. Projede, öğretim elemanları ve öğretmen hareketliliği sağlanmış; pilot bir proje olarak gerçekleştirilmiş; yabancı dille ilgili ortaklar bir araya getirilmiş ve ülkeler arasında ağ bağlantıları oluşturulmuştur. Ağ bağlantıları, proje kapsamındaki ülkeleri ziyaret ederek ve sürekli iletişim halinde olarak sağlanmıştır. Coach 4 Me projesine, dört $\mathrm{AB}$ ülkesi, bir Avrupa ülkesi (İzlanda) ile bir AB'ye aday ülke olan Türkiye dahil edilmiştir. İki yıllık bir süreyi kapsayan proje etkinliklerine, ülke ortaklarından on dört öğretmen/öğretim elemanı katılmıştır. Atölye çalışmalarına, projeye katılımcı olan ülkelerin, kendi ülkelerinden birden fazla öğreticinin katılma zorunluluğu koşulu sağlanmıştır.

Öğrencilerin günlük yaşamda artık geleneksel olan öğretim yöntemlerini sevmemeleri ve öğreticilerden farklı, yenilikçi yöntemler beklemeleri, projenin hazırlanması için esin kaynağı olmuştur. Coach 4 Me projesinde, proje süresi boyunca her ülke bir öğretim modeli (etkinliği) hazırlamış (ya da kendi eğitim sistemlerinde uyguladıkları öğretim etkinliklerini kullanmış), öğretim etkinliğini kurumunda/okulunda uygulamış ve sonrasında onu belirli bir sıralamayla gittiği ülkelerde ortaklarıyla paylaşmıştır. Diğer ortaklar ise bu etkinliği, kendi ülkelerinde uygulamışlar ve daha sonra katıldıkları toplantılarda dönüt vermişlerdir. Örneğin, belirlenen sıralamaya göre İzlanda'ya giderek öğretimsel etkinliği izleyen ortaklar, ülkelerine döndükten sonra bu öğretimsel etkinliği kurumlarında/okullarında uygulamışlar, ardından gittikleri toplantılarda dönütleri paylaşmışlardır.

Projede farklı kültürlerden öğretmenler ve akademisyenler bir arada olduğu için, aynı öğretimsel etkinlikten elde edilen dönütler ülkelere göre farklılık gösterebilmiştir. Ayrıca süreç içinde proje ortağı olan bazı ülkeler, kendileri için geliştirdikleri öğretimsel etkinliklerle projede tanıştıkları başka öğretimsel etkinlikleri birleştirerek, bam başka öğretimsel etkinlikler de üretebilmişler ve bunları toplantılarda tanıtmışlardır. Proje süreci boyunca proje ortağı ülkelerin toplantılara katılamamaları durumunda, daha sonraki toplantılara katılmaları ve tanıtılan öğretimsel etkinliği

\footnotetext{
${ }^{1}$ Projenin kabulü ve yürütülmesi esnasında kurum Nevşehir Üniversitesi olarak anılmaktaydı. İsim değişikliği 2013 yılında gerçekleşmiştir.
} 
öğrenerek sonraki toplantılarda elde ettikleri dönütleri paylaşmaları sağlanmıştır. Proje ortağı ülkelerin her birinin bir öğretimsel etkinlik üretmesi ve aynı zamanda başka ortak ülkelerden öğrendikleri öğretimsel etkinlikleri, kendi ülkelerinde uygulayarak dönüt vermek zorunda olmaları, proje katılımcılarının proje boyunca aktif olarak çalışmalarını gerektirmiştir. Ayrıca, her öğretimsel etkinlikle ilgili öğretici ve öğrencilerden, etkinliğin anlaşılabilirliği ve verimliliği hakkında görüş alınması, etkinliklerin amaçlara uygunluğu ve uygulanabilirliği açısından açıklayıcı olmuş, gelen dönütler doğrultusunda etkinlikler geliştirilmiştir.

Türkiye bu projede, Nevşehir Hacı Bektaş Veli Üniversitesi Eğitim Fakültesi tarafından temsil edilmiştir. Projenin ilk eğitim programı, 30 Aralık 2013 tarihinde proje ortaklarından Türkiye'nin ev sahipliğinde Nevşehir'de gerçekleştirilmiştir. İlk toplantıda projenin genel hatları konuşulmuş ve bir logo tasarımı planlanmıştır. Türkiye' nin ardından Kuzey İrlanda' da toplantı yapılmıştır. Üçüncü toplantı İzlanda' da, dördüncüsü İsveç'de, beşincisi İtalya'da ve son toplantı Polonya'da gerçekleştirilmiştir.

\section{Proje Süreci}

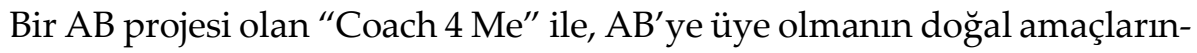
dan olan "daha geniş kitlelere ulaşma" amacının gerçekleştirilmesine çalışılmıştır. Ayrıca, "Coach $4 \mathrm{Me}^{\prime}$ projesinin tanıtımının yapıldığı bu çalışma ile, AB programları kapsamında hazırlanan projelerde ortaya çıkabilecek ürünlere yönelik farkındalık kazandırma da çalışmanın amaçları arasındadır. Bu doğrultuda çalışmada adı geçen projeden elde edilen deneyimlere yer verilmiştir.

\section{Proje Neden Önemli?}

Türkiye' de $\mathrm{AB}$ projeleri her yıl daha fazla ilgi görmekte, hazırlanan proje sayısı gün geçtikçe artmakta, bu ilgi ve katılım ise projeleri daha önemli bir hale getirmektedir. $A B$ projeleriyle farklı ülkeler, farklı kültürler ve farklı eğitim sistemlerini tanımak ve çok kültürlü ortamlar yaratmak son derecede önemlidir. AB projesi kapsamında, ülkelerin yaratıcı öğretimsel 
bir etkinlik geliştirerek eğitimsel birikimlerini ortaya koymaları ise oldukça önemli görülmektedir.

Projede, katılımcı ülkelerde faaliyet gösteren 6 farklı kurum yer almış, konuyla ilgili farklı bakış açıları bir araya getirilmeye çalışılmıştır. Proje ortaklarının bir araya gelerek çok kültürlü ortamlar oluşturmaları, birbirlerini tanımaları ve karşılıklı hoşgörünün sağlanması açısından önem arz etmektedir. $A B$ projeleri ve programları, bireyleri yabancı dil öğrenmeye de teşvik etmektedirler. $A B$, dilin toplumsal ve bilişsel boyutlarının farkına varılması ve aynı zamanda kültürel beraberliğin oluşturulması yönündeki çalışmalarıyla / projeler yoluyla dil eğitimini de desteklemektedir.

Proje, ortakları arasındaki grup dinamiğini canlı tutmak, grup motivasyonunu arttırmak ve grup çalışmalarına katkı sağlamak yoluyla; ortakların öğrenirken eğlenmesini, yapılan uygulamaları mesleki yaşamlarında kullanabilmelerini, uygulamaları kullanırken ortaya çıkabilecek aksaklıkları giderebilmeyi ve öğrenme ortamlarını eğlenceli hale getirmeyi sağlamıştır. Proje boyunca, grup üyelerinin aralarındaki etkileşimin en üst düzeye çıkarılmasına yönelik çaba sarf ettikleri görülmüştür. Uygulanmakta olan farklı programların birbiriyle daha yakın ve işbirliği içinde olmalarının faydalı olacağı düşüncesi, ortak etkinliklerin oluşturulmasına sebep olmuştur. Ortakların öğretim etkinliklerini değerlendirme becerilerini geliştirmeleri de önemli bulunmuştur. Yine, öğreticilerden ve öğrencilerden etkinliklerin verimliliği ve anlaşılabilirliği hakkında dönüt alınması, öğretimsel etkinliklerin uygulanabilirliği ve amaçlara ulaşılabilirliği açısından fikir vermiştir.

\section{Projenin Özel Amaçları:}

Projenin amaçları yaşam boyu öğrenme çerçevesinde iki başlık altında incelenmiştir:

\section{Mesleki Amaçlar:}

- Yaşam boyu eğitim / mesleki deneyim ve yeterliklerin kalitesini arttırmak,

- Ülkelerarası teknolojik ve kurumsal değişiklikleri bütünleştirmek, 
- Mesleki eğitim kurumları ile işletmeler arasında işbirliğini geliştirmek,

- İstihdam imkânlarını arttırmak,

- Sürekli mesleki eğitim ve yaşam boyu öğrenme isteğini güçlendirmek,

- Yarının mesleklerine hazırlanma ve teknolojik değişimlere uyumu teşvik etmek,

- Mesleki eğitim alanında, dil yeterliliklerinin geliştirilmesi ve ortak bir terminolojinin oluşturulmasını sağlamak,

- Özellikle gençler için temel mesleki eğitimi desteklemek ve teşvik etmek,

- Mali, sosyal veya fiziksel nedenlerle eğitimden yararlanamamış kişiler için temel mesleki eğitime veya ileri düzeydeki eğitimlere erişimi kolaylaştırılmak.

\section{Öğretimsel Amaçlar:}

- Eğiticilere/öğretmenlere sınıflarında yeni öğretme becerileri ve yeterlikleri kazandırmak,

- Sınıf yönetimi performanslarını arttırmak,

- Heterojen gruplara daha kolay ulaşmak, geleneksel öğretimin dişına çıkarak kişisel ve sosyal beceriler geliştirmek,

- Kültürlerarası, farklı kuşaklarda ortaya çıkan çatışmaları en aza indirerek, bunlarla baş edebilmeyi öğretmek,

- Avrupa düzeyinde iyi öğretimsel etkinlikleri paylaşabilmek,

- Öğretimsel etkinlikleri sınıflara taşıyabilmek,

- Her ortağın uyguladığı farklı ve etkili öğretim yöntem ya da modelini incelemek ve kendi ülkesine uyarlayarak uygulama sonuçlarını değerlendirmek,

- Ortaklar arasındaki grup dinamiğini canlı tutmak ve motivasyonu arttırmayı sağlamak.

\section{Projenin Katılımcıları:}

Her ülkenin kendi bütçesine göre bir katılımcı listesi bulunmaktadır ve her oturumda katılımcı sayısı değişmektedir. Çünkü projeye katılan daimi araştırmacılar dışında, hareketlilik kapsamında ülkelerden gelen farklı 
katılımclar da mevcuttur. Projedeki katılımcı insan kaynakları özellikleri, katılan kurumun özelliklerini yansıtmakta, duruma göre akademisyenler kurum yöneticileri ya da öğretmenlerden oluşmaktadır. Kurumlara göre katılımcı özellikleri aşağıda verilmektedir:

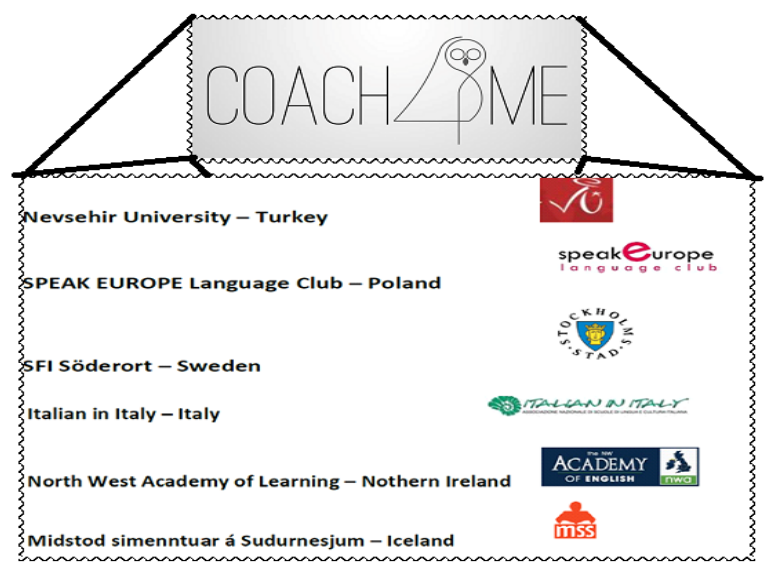

Şekil 1. Coach 4 Me Proje Katılımcıları

- Türkiye: Nevşehir Hacı Bektaş Veli Üniversitesi'nin çeşitli fakültelerinden bütçeleme hareketlilik kapsamında kurum yetkilisi tarafından seçilen öğretim üyeleri.

- Polonya: SPEAK EUROPE Language Club'da görevli kurum araştırmacıları ve dil öğretmenleri.

- İsveç: SFI Söderort'da kurum araştırmacıları ve dil öğretmenleri.

- İtalya: Italian in Italy'de görevli kurum araştırmacıları ve dil öğretmenleri.

- Kuzey İlanda: North West Academy of Learning'te görevli bir proje yürütücüsü ve kurum öğretmenleri.

- İzlanda: Midstod simenntuar á Sudurnesjum'da görevli bir proje yürütücüsü ve kurum öğretmenleri.

\section{Projenin Uygulama Süreci}

İki y1lı kapsayan (2013-2015) uygulama sürecindeki etkinliklere ülkeler, Türkiye' nin ev sahipliğinde başlamışlardır. 
İlk Buluşma Türkiye ve Planlanan Etkinlikler: Türkiye buluşması, uygulamalardan ziyade, yapılacak etkinliklerin planlanması şeklinde bir gelişim göstermiştir. Proje logosu ve web sayfası, projenin sosyal medyada tanıtımı ve sosyal medya üzerinden bilgi paylaşımı sorunlarına bu oturumda çözümler üretilmiştir. Ayrıca katılımcı kurumlar kendilerini tanıtmışlar, gelecekte yapılacaklar konuşulmuştur. Katılımcılar Kapadokya'nın büyüleyici atmosferinde ağırlanmışlar ve bir Türk gecesine katılımları sağlanmıştır.

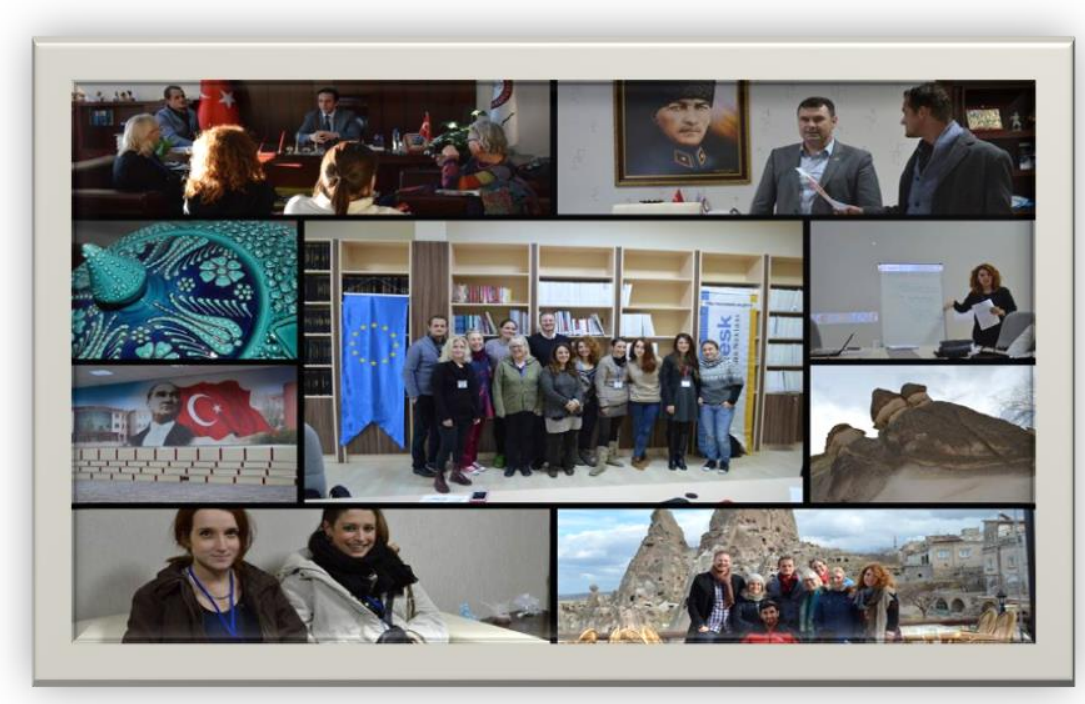

Fotoğraf 1. Türkiye İzlenimleri

Kuzey İrlanda ve İlk Yaratıcı Uygulamalar, GROW Model (Goal, Reality, Objective, Will): İlk yaratıcı öğretim uygulaması örneği (GROW Model, Goal, Reality, Objective, Will), katılımcılara Kuzey İrlanda tarafından sunulmuştur. Bir öğrenciyle karşılıklı çalışılarak, öğrencinin problemi ve amaçları üzerinden, problem çözme becerisini güçlendirmek amaçlanmıştır. Bu etkinlik diğer ülke katılımcıları eğitmenlerine öğretilmiş ve kendi ülkelerindeki uygulama deneyimlerini bir sonraki buluşma için hazırlamaları istenmiştir. 
İzlanda, Ülkelerin Kuzey İrlanda'nın Önerdiği Öğretim Etkinliğini Sunumları ve İsveç'in Sunumu, Mediation Model: İzlanda'da bir araya gelindiğinde, ülkelerin kendi eğitim sistemlerinde GROW Modeli uygulamaları izlenmiş ve değerlendirilmiş, oldukça yoğun bir program yürütülmüştür. Bu oturumda aynı zamanda İzlanda öğretim etkinliği olan Mediation Model'in uygulanışını diğer ülkelere öğretmiştir. İzlanda'nın muhteşem gayzerleri ve okyanus balinaları izlenmiş, Bluee Lagoon ziyareti gerçekleştirilmiştir.

İsveç Buluşması, Ev Sahibi Etkinlik Five Beautiful Words'ün Uygulanması, Mediation Model'in Diğer Ülkelerce Uygulanması ve Polonya'nın Etkinliği Maps and Territories Model: İsveç'te daha önceki buluşmalara göre, zaman daha uzun planlanmıştır. Tüm ülkeler Mediation Model'in kendi ülkelerinin eğitim sistemlerindeki uygulamalarını sunmuşlar, devamında Polonya'dan gelen katılımclar kendi ülkelerine özgü öğretim etkinliği Maps and Territories Model'i diğer ülkelere öğretmişlerdir. İsveç de bu buluşmada, kendi etkinliği Five Beautiful Words'ü diğer katılımcı ülkelere öğretmiştir.

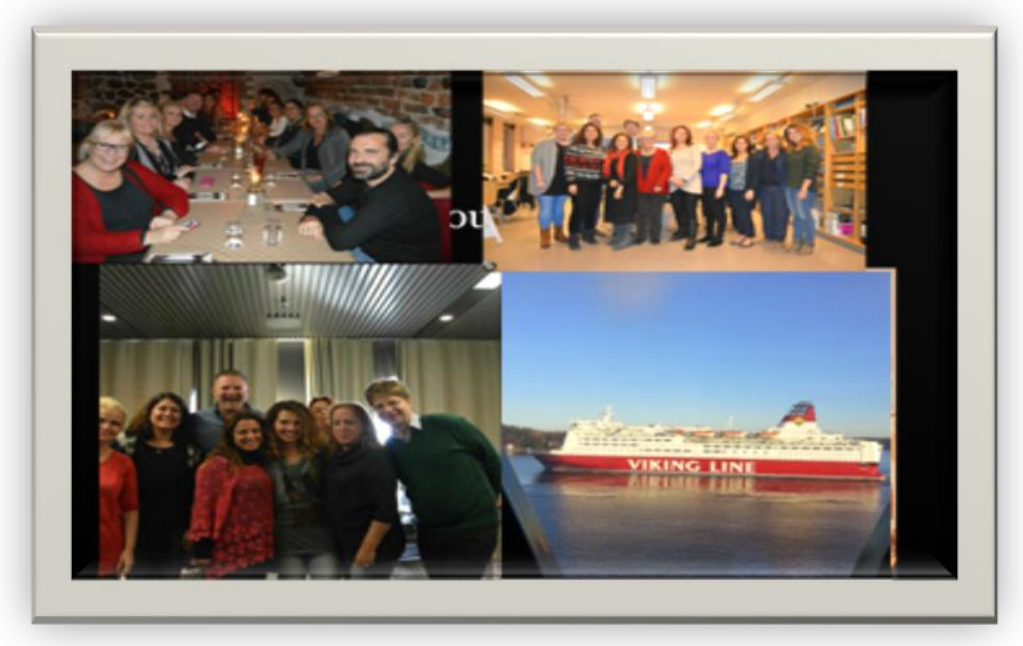

Fotoğraf 2. Isveç İlenimleri 
Bu buluşmada tüm etkinlikler bir gemide ve İsveç Finlandiya arasındaki deniz yolculuğu esnasında geçekleştirilmiştir. Yolculuk bitimi İsveç fyörkleri izlenmiş, geleneksel bir İsveç restoranında akşam yemekleri yenmiştir. İsveç'teki konaklama alanı, artık denize açılmayan bir gemiden hizmete sunulan ilginç bir oteldir.

İtalya, Maps and Territories Model'in Diğer Ülkelerce Uygulanması,
İtalya'nın Etkinliği Seven Steps ve Türkiye'nin Etkinliği, Creative Images of Concept: Daha çok yabancı dil öğretiminde uygulanmaya uygun olan Seven Steps'in, öğrencilerin zihinlerinde yaratıcı imgeler oluşturmaya yarayan Creative Images of Concept'in ülkelere öğretilmesi, katılımcılara çok yoğun ve eğlenceli anlar yaşatmıştır. Türkiye, çalışmasında, öğretmen adaylarının bir kavram üzerinden yaratıcı imgeler oluşturarak, bunu öğretimsel etkinliğe dönüştürmesini modellemiş, İtalya, fotoğraflar üzerinde duyguları temsil eden renklerle betimletmiştir. Katılımcıların renk tercihleri fotoğraflar üzerindeki duygusal anlamları yeniden resmetmeyle sonuçlanmıştır. İki Akdeniz ülkesinin insanlarının sıcaklığı, tüm proje katılımcılarına da yansımıştır.

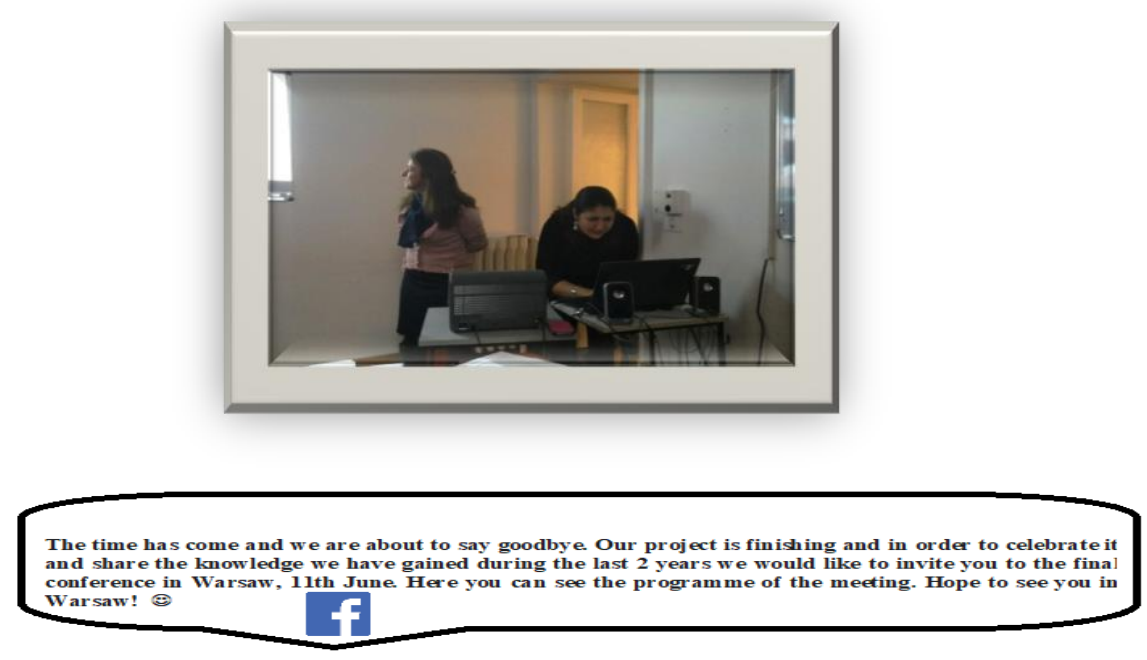

Fotoğraf 3. İtalya İzlenimleri 
Polonya, Veda Vakti, Genel Değerlendirme: Polonya'da, projenin son iki etkinliğinin ülkelere göre uyarlama deneyimleri ile eksik uygulaması bulunan ülkelerin çalışmaları izlenmiştir. Bir genel değerlendirme toplantısı da yapılmış, projenin raporlaştırılmasına ilişkin bilgi paylaşımlarında bulunulmuştur.

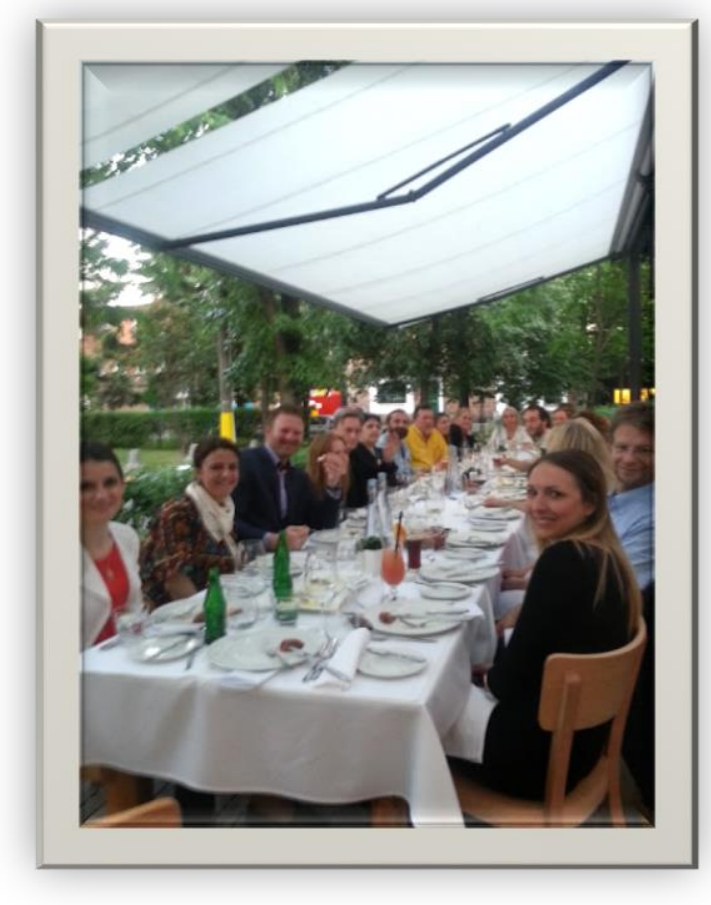

Fotoğraf 4. Polonya İzlenimleri

Toplantıda ayrıca, ülkelerin önerdiği her etkinlik uygulaması için yerel dönütleri incelenmiş, uygulamalarda karşılaşılan zorluklar tartışılmış, gerektiğinde farklı görüşler model öğretim etkinliklerin gelişimini destekliyorsa, gerekli revizyonların yapılması sağlanmıştır. Yaratıcı bir öğretim etkinliğinin yaratıcı bir başka öğretim etkinliğine esin kaynağ olabilmesine çalışılmış, yeni etkinlik önerileri üzerinde yeni değerlendirmeler yapılmıştır. 


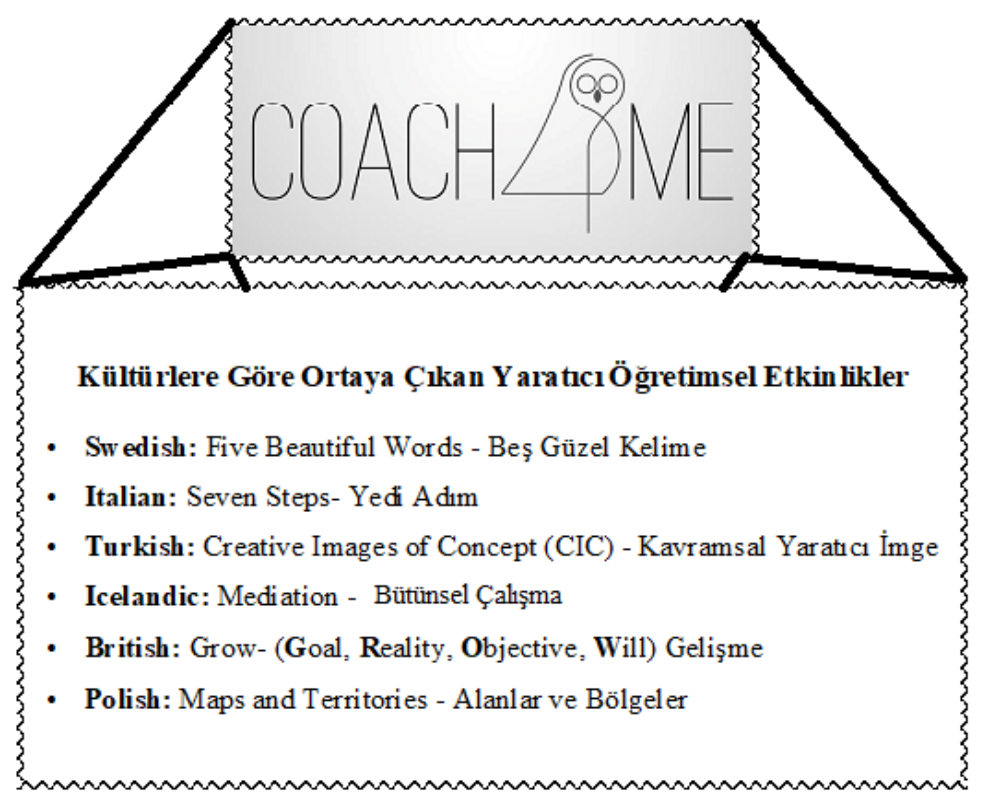

Şekil 2. Kültürlere Göre Ortaya Çıkan Bazı Yaratıcı Öğretimsel Etkinlikler

\section{Sonuç ve Tartışma}

$A B$ projeleri $A B$ ve diğer ülkeler arasında var olan eğitimsel ve kültürel etkileşimin artmasına katkıda bulunmaktadır. Uluslararası kuruluşlar ve topluluklar arasında yer alan $\mathrm{AB}$, ekonomik ve siyasi alanda yürüttükleri işbirliğinin yanı sıra, eğitimi çağın gelişmelerine uyarlamak ve kaliteyi arttırmak için bir çok uluslararası proje ve faaliyet ortaya koymakta ve yürütmektedirler (Aydoğan \& Şahin, 2006, 456). Bu faaliyetlerden biri de Avrupa Birliği Eğitim Programları gibi uluslararası eğitim çalışmalarıdır. Eğitim çalışmaları bazen okullarla, bazen sivil toplum kuruluşları ile bazen de yükseköğretimle yapılmaktadır. Tüm bu çalışmalar ülkelerarası etkileşimi ve iletişimi sağlamakla birlikte, farklılıklara saygıyı da öğretmektedir.

Coach $4 \mathrm{Me}$, öğretmen eğitimi süreçlerinde, meslek öncesi, mesleki eğitim esnasında ve sonrasında, öğretmen, öğretmen adayı ve öğretmen eğitimci akademisyenleri, öğretmenlik yetilerini yaratıcılığa taşıma noktasında geliştirici özel bir güce sahip kılmıştır. Bu bağlamda, öğretimsel 
süreçlere pratikte yeni ve yaratıcı değerler katarken, uygulama periyotlarında, öğrenme-öğretme süreçleri üzerinde kuramsal anlamda yeniden düşünme, karşılaştırma ve değerlendirme olasılıklarını da aktif hale getirmiştir.

Konokman, Akay \& Demircioğlu (2015) öğretim elemanlarının görüşüne dayanarak $\mathrm{AB}$ projelerinin bilimsel çalışma üretmeye, motivasyon sağlamaya, özgüven oluşturmaya, girişimcilik ve problem çözme becerisini geliştirmeye katkı sağladığını belirtmişlerdir. Bu projede de benzer süreçlere şahit olunmuştur.

Ortak bilimsel ve sosyal amaca hizmet eden projelerin, sonuçlandırıldıklarında, ürettikleri değerlerini başka platformlarda paylaşmaları, başka projelere örnek ve öncü olmaları, gelecek yeni projeler için ateşleyici bir güce sahip olmaları gerekmektedir. Bu bağlamda, bu tür projelerin tanınırlıklarını ve katma değerlerini arttırmak için, akademik platformlarda tanıtılmaları, projenin her hangi bir aşamasına küçük de olsa bir dokunuşu bulunan aslında tüm katılımcıların gönüllerindeki ifadeleri somutlaştırmanın bir başka yoludur.

Bu projenin, gelecekteki projelere projeksiyonu ise şöyledir: Her türlü bilimsel, sosyal ve evrensel içeriği olan projelerde olduğu gibi, AB Projelerine de katılımlar teşvik edilmelidir. Özellikle bu katılımlarda, katılımcıların yeni projeler üretme becerilerinin gelişimine katkı verilmeye çalışılmalıdır. Bu projenin uygulama örnekleri başka bir çalışmada detaylı olarak incelenecektir. 


\section{EXTENDED ABSTRACT}

\section{Coach 4 Me: Experience of a Leonardo Da Vinci Project for Teacher Education}

\section{E. Zehra Turan - Aysun Erginer - Ergin Erginer - Funda N. Yılmaz Nevşehir Hacı Bektaş Veli University}

The EU, which comes from the idea of combining their powers, using their existing resources together and developing together, started with 6 member countries it continues its journey with 28 candidate countries. In addition, including Turkey there are countries waiting to be candidates for the EU. The EU, which was initially formed as an economic and political structure, also contributes to the achievement of educational and cultural gains. EU countries implement some training programs and projects by signing agreements in educational and cultural fields, including candidate countries. One of the countries implementing for EU programs and projects is Turkey.

Erasmus + has been established with the inclusion of Comenius, Erasmus, Leonardo da Vinci, Grundtvig Programs, Youth Program and 5 International Cooperation Programs (Erasmus Mundus, Tempus, Alfa, Edulink and Cooperation Program with Industrialized Countries) covered within the scope of Lifelong Learning Programs. Thus, with the transition to a single program, the application of fragmented structure was abandoned and the application conditions were simplified. With Erasmus +, EU education programs have turned into a supportive program for different age groups and target groups in the fields of education, youth and sports. There are included in this program projects related to "school education, higher education, vocational education, adult education, youth and sports".

Various applications for lifelong learning, the European Union (EU) by being supported under the Erasmus + Leonardo da Vinci Program, are projected through national agencies and non-governmental organizations of the countries. The Leonardo da Vinci Program is a training program 
conducted to support and develop the policies and practices of EU member and candidate countries for vocational education. Within the scope of this training program one of the projects prepared is "Coach $4 \mathrm{Me}^{\prime}$ is named project. "Coach 4 Me", "Turkey, Northern Ireland, Iceland, Sweden, Italy and Poland", including carried out by 6 countries and academics with teachers to improve teaching skills, it is a 2-years project. Introducing the project to a wider audience and using instructional activities in different educational environments after the process have been determined as sustainable objectives in the project.

Coach 4 Me project in scope, making its first meeting in Turkey, the project's goals, things to do, logo of project etc. are detected; then, the project was carried out by meeting in the partner countries according to the above mentioned ranking. In the project, each country was asked to produce a teaching model (activity) or to present an instructional activity used in the country. After Turkey, project partner traveled to other countries, were introduced instructional effectiveness of the host country, the activity was implemented with participants and thus it was tried to learn. Then, in the next country, the instructional activity in the previous country, the project partners were asked to be tested in their country's schools / institutions; the feedback received from the instructors and students on the comprehensibility and efficiency of the activity was shared in the next meeting and the instructional effectiveness of the host country was introduced and implemented. In the country where the last meeting was held, for the instructional activities previously introduced, the applications and feedback were shared in the partner countries, the project was completed by evaluating the project.

At the end of the practices, it was observed that countries produced activities reflecting their own culture. For example, Northern Ireland proposed as an activity to strengthen the problem-solving skills of the student their problems and goals. Turkey asked teacher candidates to produce creative images through a concept and has been modeled into

the instructional activities. Italy described the participants to their feelings using colors. When the participants used color preferences, they marked the colors on the photos and the photos gained a new meaning 
with new colors. Emotions have been re-expressed in colors and the emotions in the photographs have deeper and new meanings.

As a result of the project, original instructional activities were produced to refer teachers to new teaching practices. At the end of the project, the participants had happy learning environments and invaluable learning experiences in their group dynamics.

\section{Kaynakça/References}

Aydoğan, İ., ve Şahin, A. E. (2006). Comenius okul ortaklıkları projelerinin, Comenius amaçlarının gerçekleşmesine katkısı. Kuram ve Uygulamada Ĕ̆itim Yönetimi, 48, 455-480.

Ertl, H. (2003). The European Union and education and training: An overview of policies and initiatives. İçinde: David Phillips \& Hubert Ertl (ed.) Implementing European Union education and training policy: A Comparative Study of Issues in Four Member States,(s: 13-39), Netherland: Kluwer Academic Publishers.

Kesik, F. ve Balcı, E. (2016). AB projelerinin okullara sağladığı katkılar açısından değerlendirilmesi: Bir ölçek geliştirme çalışması. Kastamonu Ĕ̆itim Dergisi, 24(4), 1621-1640.

Konokman, G. Y., Akay, C., ve Demircioğlu, T. (2015). Eğitim fakültesi öğretim elemanlarının Avrupa Birliği hayat boyu öğrenme projelerine bakışı. Journal of International Social Research, 8(38), 773-790.

Kulaksız, E. (2010). Avrupa Birliği Comenius programlarının Türkiye'deki uygulamasına ilişkin katılımo görüşleri. Yayımlanmamış Doktora Tezi, Kocaeli Üniversitesi, Kocaeli.

Maya, İ. Ç. (2006). AB sürecinde Türkiye ile AB ülkeleri eğitim istatistiklerinin karşılaştırması. Türk Eğitim Bilimleri Dergisi, 4(4), 375-394.

Passmore, J. (2014). Mastery in coaching. Kogan Page . UK.

UA. (2011a). Leonardo Da Vinci mesleki eğitim programı: yenilik transferi. http://www.ua.gov.tr/uploads/leonardodavinci/TOI/2011_TOI_TANITIM.pps\#256,1,Slayt 1, Erişim tarihi: 15.6.2011.

UA. (2011b). Leonardo Da Vinci mesleki eğitim programı: ortaklık projeleri. http://www.ua.gov.tr/uploads/leonardodavinci/partnership/2011Ortakliklar.ppt, Erişim Tarihi: 15.6.2011. 
UA. (2015). Faaliyet Raporu, http://www.ua.gov.tr/in-dex.cfm?action=detay\&bid=9, Erişim Tarihi: 1.1.2015.

UA. (2018a). ERASMUS+'ı Merak mı Ediyorsunuz? http://www.ua.gov.tr/kurumsal/halkla-ili\%C5\%9Fkiler/erasmus-\%C4\%B1-merak-m\%C4\%B1-ediyorsunuz-, Erişim Tarihi: 13.2.2018.

UA. (2018b). TC. Avrupa Birliği Bakanlı̆̆ı AB Ĕ̆itim ve Gençlik Programları Merkezi Başkanlığı. Erasmust Leonardo da Vinci Programı. http://www.ua.gov.tr/programlar/erasmus-program\%C4$\%$ B1/mesleki-e\%C4\%9Fitim-program\%C4\%B1, Erşim Tarihi: 30.1.2018.

UA. (2018c). Türkiye Ulusal Ajansı. Erasmus+ Programinda Hangi Ülkeler Yer Aliyor? http://www.ua.gov.tr/programlar/erasmus-program\%C4\%B1, Erişim Tarihi: 16.2.2018.

Uysal, T. (2004). Leonardo Da Vinci II programı. İstanbul: IKV.

Ünal, M. (2016). Öğretim elemanı ve öğrencilerin AB Erasmus+ Programın algılama durumlarının incelenmesi, Ahi Evran Üniversitesi Kırşehir Eğitim Fakültesi Dergisi (KEFAD), 17(3), 581-598.

Yazg1, C. (2010). Avrupa birliği bilgi toplumu projeleri ve üniversite kütüphaneleri. Yayımlanmamış Yüksek Lisans Tezi, Marmara Üniversitesi, İstanbul.

\section{Kaynakça Bilgisi / Citation Information}

Turan, E. Z., Erginer, A., Erginer, E. ve Nalbantoğlu-Yılmaz, F. (2018). Coach 4 Me: Öğretmen eğitiminde kullanılabilecek bir Leonardo Da Vinci projesi deneyimi. OPUS-Uluslararası Toplum Araştırmaları Dergisi, 9(16), 2597-2617. DOI: 10.26466/opus.498760 